\title{
PENGARUH VARIASI VOLUME SALURAN PENAMBAH (RISER) TERHADAP CACAT POROSITAS DAN STRUKTUR MIKRO KOMPONEN TUTUP MESIN MOTOR LISTRIK
}

\author{
Rizal Rahma Sandi1 dan Heri Yudiono² \\ 1)Pendidikan Teknik Mesin, Jurusan Teknik Mesin, Fakultas Teknik, \\ Universitas Negeri Semarang \\ 2)Teknik Mesin, Jurusan Teknik Mesin, Fakultas Teknik, \\ Universitas Negeri Semarang \\ Heri_yudiono@mail.unnes.ac.id
}

\begin{abstract}
ABSTRAK: Penelitian ini bertujuan untuk menguji pengaruh volume saluran penambah terhadap cacat porositas pada coran aluminium dan struktur mikro hasil pengecoran aluminium. Metode yang digunakan adalah metode Pre-eksperimen jenis One-Shot Case Study, karena dalam penelitian ini akan dilakukan perlakuan yang selanjutnya akan diobservasi hasilnya. Perlakuan yang akan dilakukan yaitu dengan penambahan variasi tidak memakai saluran penambah, variasi saluran penambah silinder dengan diameter $15 \mathrm{~mm}$ dan tinggi $60 \mathrm{~mm}$, variasi saluran penambah silinder dengan diameter $25 \mathrm{~mm}$ dan tinggi $60 \mathrm{~mm}$, variasi saluran penambah silinder dengan diameter $35 \mathrm{~mm}$ dan tinggi $60 \mathrm{~mm}$. Pengujian struktur mikro menggunakan alat uji Meji Techno IM 7200. Analisis data yang digunakan adalah analisis deskriptif untuk memberikan deskripsi mengenai subjek penelitian berdasarkan data dari variabel yang diperoleh dari kelompok subyek yang diteliti. Hasil porositas yang terbaik ditunjukkan oleh spesimen hasil coran dengan variasi saluran penambah diameter $35 \mathrm{~mm}$ sebesar $37,97 \%$. Struktur mikro yang terbaik ditunjukkan oleh spesimen hasil coran dengan variasi saluran penambah diameter $35 \mathrm{~mm}$ dibuktikan dengan pembentukan fasa struktur yang lebih rapat dan merata.
\end{abstract}

Kata kunci: saluran penambah, cacat porositas, struktur mikro, dan coran aluminium

\section{PENDAHULUAN}

Motor listrik merupakan perangkat yang sering digunakan dalam dunia otomotif dan perindustrian. Seiring dengan usia pemakaian maka akan terjadi kerusakan. Seperti keausan pada beberapa komponen motor listrik, terutama komponen yang terus menerus bergerak dan bergetar, diantaranya yaitu bearing, poros, dan tutup motor listrik yang menjadi tempat bantalan dari bearing.
Salah satu unsur penting yang perlu diperhatikan dalam memproduksi produk cor yang berkualitas tinggi adalah perancangan saluran (gating design). Upaya penelitian secara meluas telah banyak dilakukan untuk mempelajari pengaruh perancangan sistem saluran pada pola aliran logam cair saat memasuki cetakan. Perancangan sistem saluran yang optimal dapat mengurangi turbulensi pada aliran logam cair, meminimalisasi udara yang terjebak, inklusi pasir, 
terbentuknya lapisan oksida dan terak (Rizuan, 2009).

Cacat coran tersebut dipengaruhi oleh banyak hal salah satunya adalah desain sistem saluran yang kurang baik. Sistem saluran pada cetakan pasir meliputi cawan tuang, saluran turun (sprue), dam atau waduk, saluran pengalir (runner), saluran penambah (riser), dan saluran masuk (ingate). Penelitian ini akan mendalami tentang volume saluran penambah (riser). Saluran penambah memiliki peranan penting karena merupakan saluran dimana logam cair akan keluar dari rongga cetakan. Dengan mempertimbangkan volume saluran penambah diharapkan akan mengurangi resiko terjadinya cacat yang sering timbul pada sand casting.

Pembuatan cetakan, jenis pasir yang akan digunakan dalam penelitian ini adalah pasir daerah juwana. Proses pengecoran dengan menggunakan cetakan pasir sendiri tidak lain adalah menuangkan logam cair kedalam rongga dari cetakan pasir serta laju pendinginan pada benda coran, sehingga aliran pada rongga cetakan proses pengecoran mempunyai peranan penting dalam pembentukan srtuktur mikro, dimana struktur mikro mempengaruhi sifat mekanik yang dimiliki oleh benda cor (Gaspari, 1999). Pada proses penuangan aliran logam cair harus diperhatikan, rongga cetakan yang kurang tepat menyebabkan cacat produk. Sedangkan bahan yang digunakan dalam penelitian ini adalah logam aluminium, aluminium merupakan material yang menarik karena bersifat ringan, penghantar panas yang baik, tahan korosi, dan mempunyai titik lebut yang relatif rendah sehingga material ini juga mudah didaur ulang.

proses pengecoran pasir terdiri dari gating system yang mengirim logam cair ke dalam rongga cetakan dimana logam cair diubah menjadi produk padat. Logam cair dituangkan ke dalam cetakan melalui gating system dan mengalir melalui rongga, akhirnya mencapai riser. Diketahui bahwa logam cair telah mencapai riser, menuangkan logam cair dihentikan. Karena riser yang diposisikan lebih tinggi dari rongga, energi potensinya lebih tinggi daripada logam cair dalam rongga (Jin, dkk, 2017). Dengan pengaturan ini, logam cair di dalam riser mengkompensasi pengurangan volume karena penyusutan selama pemadatan logam cair ketika dipadatkan di dalam cetakan. Oleh karena itu, logam cair di dalam riser harus dipadatkan pada tahap selanjutnya dari logam cair di dalam rongga. Jika ukuran riser cukup dirancang, rongga penyusutan yang dihasilkan di dalam cetakan berkurang, dan struktur padat dapat diperoleh dalam produk casting yang menghasilkan pengecoran berkualitas tinggi. Namun, jika ukuran riser tidak dirancang dengan benar (riser terlalu besar), produktivitas dipengaruhi karena biaya material yang tinggi, tingkat pemulihan rendah, waktu pemadatan yang lebih lama, dan proses pascapanjang untuk menghilangkan riser. Di sisi lain, jika ukuran riser terlalu kecil, dihasilkan pengecoran yang rusak. Karena cacat coran adalah masalah terbesar yang terjadi dalam proses, perusahaan casting menggunakan riser lebih besar dari ukuran produk untuk proses casting dan struktur padat dapat diperoleh dalam produk casting, yang menghasilkan casting berkualitas tinggi.

Penelitian ini memfokuskan pada pengaruh variasi volume riser terhadap struktur mikro dan cacat porositas dari hasil pengecoran aluminium sandcasting. Variasi volume riser yang berbeda pada gating system akan menghasilkan struktur mikro dan komposisi produk yang berbeda. Dan hal tersebut akan menghasilkan ketahanan aus yang berbeda. Penelitian menggunakan pengujian ketahanan aus 
untuk mengetahui angka keausan dari hasil coran, hal ini merupakan salah satu sifat mekanik yang penting. Serta pengujian struktur mikro yang digunakan untuk memperoleh gambar struktur logam hasil coran. Untuk tujuan tersebut penulis tertarik untuk meneliti seberapa pengaruh volume saluran penambah pada cetakan pasir terhadap kualitas benda hasil pengecoran remelting aluminium dari piston bekas.

\section{METODE}

Desain penelitian yang digunakan yaitu Pre-eksperimen jenis One-Shot Case Study, karena dalam penelitian ini akan dilakukan perlakuan yang selanjutnya akan diobservasi hasilnya.

Perlakuan yang akan dilakukan yaitu dengan penambahan variasi tidak memakai saluran penambah, 1 pola untuk variasi saluran penambah silinder dengan diameter $15 \mathrm{~mm}$ dan tinggi $60 \mathrm{~mm}$, 1 pola untuk variasi saluran penambah silinder dengan diameter $25 \mathrm{~mm}$ dan tinggi $60 \mathrm{~mm}$, 1 pola untuk variasi saluran penambah silinder dengan diameter $35 \mathrm{~mm}$ dan tinggi $60 \mathrm{~mm}$. pada cetakan pasir untuk mengetahui hasil pengamatan struktur mikro dan cacat porositas pada hasil pengecoran aluminium piston bekas.

Bahan Penelitian yang digunakan adalah aluminium bekas, pasir cetak, air dan bahan bakar. Alat uji struktur mikro menggunakan alat uji Meji Techno IM 7200. Alat uji cacat porositas menggunakan timbangan digital dengat ketelitian 0,01 dan gelas. dimensi spesimen uji ketahanan aus mengacu pada standar yang sudah ditetapkan yaitu menggunakan standar Instruction Manual Meji Techno IM 7200.

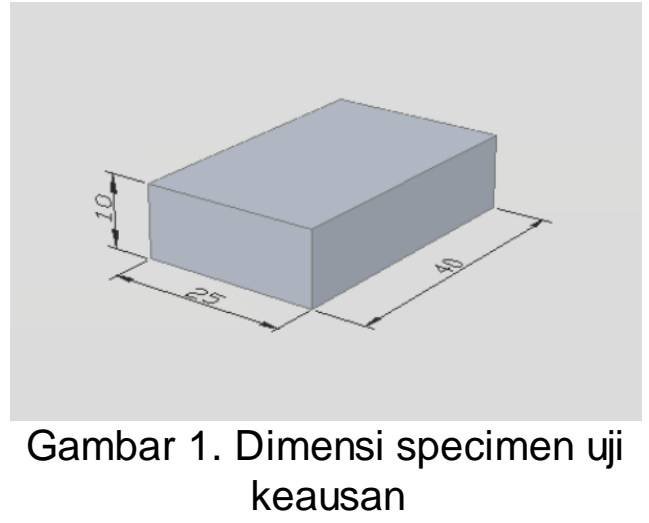

Variabel bebas dalam penelitian ini yaitu variasi tidak memakai saluran penambah, variasi saluran penambah silinder dengan diameter $15 \mathrm{~mm}$ dan tinggi $60 \mathrm{~mm}$, variasi saluran penambah silinder dengan diameter $25 \mathrm{~mm}$ dan tinggi $60 \mathrm{~mm}$, variasi saluran penambah silinder dengan diameter $35 \mathrm{~mm}$ dan tinggi $60 \mathrm{~mm}$ dalam pasir cetak. Variabel terikat dalam penelitian ini yaitu porositas, struktur mikro, dan ketahanan aus. Variable kontrol dalam penelitian ini yaitu bahan yang diguakan yaitu aluminium tutup motor listrik bekas, benda kerja memiliki dimensi yang sama untuk semua spesimen, menggunakan pasir yang sama pada semua spesimen yaitu pasir juwana dengan mesh 90, menggunakan kadar air yang sama pada pasir yang akan digunakan dan suhu pembakaran saat proses penuangan sama yaitu $690^{\circ} \mathrm{C}$.

\section{HASIL DAN PEMBAHASAN}

\section{Hasil}

Pengujian komposisi bertujuan untuk mengetahui unsur unsur pembentuk dari benda yang akan diuji, ini berguna untuk menganalisa kekuatan mekanis yang dimiliki oleh benda uji. Berikut ini adalah hasil pengujian komposisi dari produk coran.

1. Kandungan tutup mesin motor listrik mobil kijang 
Tabel 1. Unsur dari tutup mesin motor listrik

\begin{tabular}{|l|l|}
\hline Unsur & $\begin{array}{l}\text { Kadar } \\
\%\end{array}$ \\
\hline $\mathbf{A l}$ & 84,56 \\
\hline $\mathbf{S i}$ & 12,6 \\
\hline $\mathbf{F e}$ & 1,1 \\
\hline $\mathbf{C u}$ & 0,126 \\
\hline $\mathbf{M n}$ & 0,264 \\
\hline $\mathbf{M g}$ & $<0,05$ \\
\hline $\mathbf{C r}$ & $<0,015$ \\
\hline $\mathbf{N i}$ & $<0,02$ \\
\hline $\mathbf{Z n}$ & 1,13 \\
\hline $\mathbf{S n}$ & 0,0556 \\
\hline $\mathbf{T i}$ & 0,0099 \\
\hline $\mathbf{P b}$ & $<0,03$ \\
\hline $\mathbf{B e}$ & 0,0001 \\
\hline $\mathbf{C a}$ & 0,0061 \\
\hline $\mathbf{S r}$ & $<0,0005$ \\
\hline $\mathbf{V}$ & $<0,01$ \\
\hline $\mathbf{Z r}$ & $<0,003$ \\
\hline
\end{tabular}

2. Kandungan coran aluminium campuran

Tabel 2. Unsur coran aluminium campuran

\begin{tabular}{|l|l|}
\hline Unsur & $\begin{array}{l}\text { Kadar } \\
\%\end{array}$ \\
\hline $\mathbf{A l}$ & 68,51 \\
\hline $\mathbf{S i}$ & 21,3 \\
\hline $\mathbf{F e}$ & 6,62 \\
\hline $\mathbf{C u}$ & 0,680 \\
\hline $\mathbf{M n}$ & 0,0202 \\
\hline $\mathbf{M g}$ & 0,296 \\
\hline $\mathbf{C r}$ & $<0,015$ \\
\hline $\mathbf{N i}$ & 0,175 \\
\hline $\mathbf{Z n}$ & 0,0603 \\
\hline $\mathbf{S n}$ & $<0,05$ \\
\hline $\mathbf{T i}$ & 0,0244 \\
\hline $\mathbf{P b}$ & 0,256 \\
\hline $\mathbf{B e}$ & 0,0003 \\
\hline $\mathbf{C a}$ & 0,0036 \\
\hline $\mathbf{S r}$ & $<0,0005$ \\
\hline $\mathbf{V}$ & 1,57 \\
\hline $\mathbf{Z r}$ & 0,0467 \\
\hline
\end{tabular}

Pengujian porositas merupakan pengujian untuk memeriksa cacat pada coran. Pengujian ini dilakukan dengan dua tahap yaitu tahap penghitungan densitas benda hasil coran lalu dengan menggunakan perbesaran gambar dengan foto mikro sehingga hasil yang didapat valid dan saling menguatkan. Untuk menguji nilai porositas spesimen digunakan dengan menghitung berat spesimen di udara dan menghitung berat spesimen di air, setelah itu dilakukan perhitungan porositas melalui rumus. Ukuran spesimen adalah $40 \mathrm{~mm}$ $\times 25 \mathrm{~mm} \times 10 \mathrm{~mm}$.

Agar mempermudah pembacaan tabel dari perhitungan porositas maka dibuat grafik seperti pada gambar 5 .

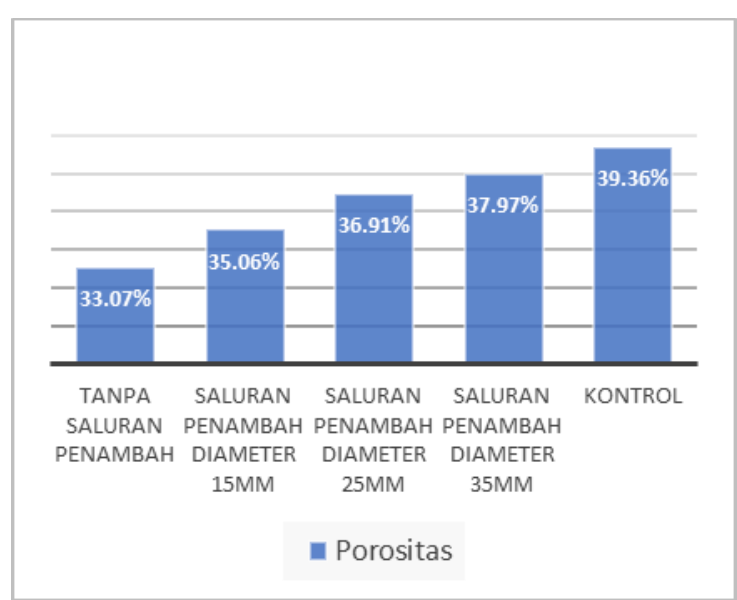

Gambar 2. Penggambaran hasil porositas menggunakan grafik batang

Untuk lebih menguatkan data pengukuran, dilakukan uji foto mikro dengan perbesaran sebesar 100x dan hasil fotonya sebagai berikut:

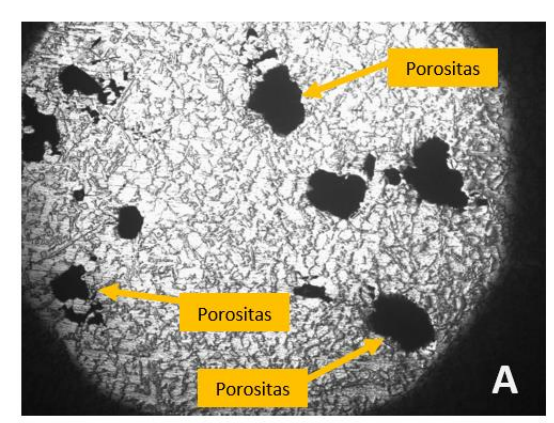

Gambar 3. Foto mikro porositas spesimen variasi tanpa saluran 


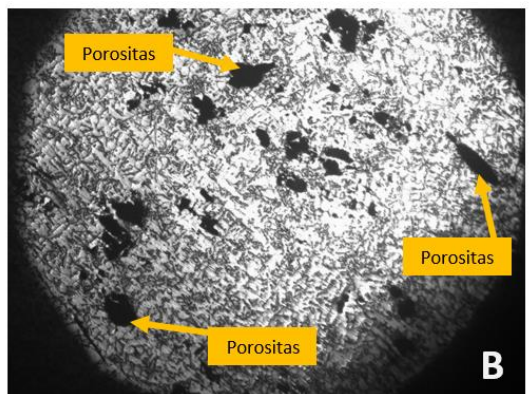

Gambar 4. Foto mikro porositas spesimen variasi saluran penambah diameter $15 \mathrm{~mm}$

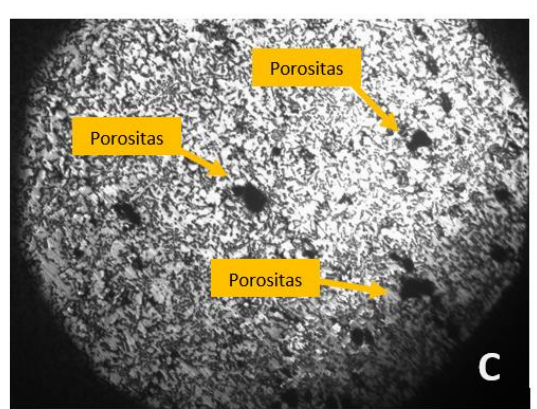

Gambar 5. Foto mikro porositas spesimen variasi saluran penambah diameter $25 \mathrm{~mm}$

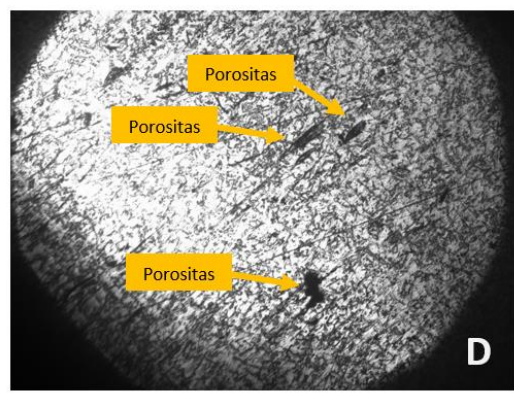

Gambar 6. Foto mikro porositas spesimen variasi saluran penambah diameter $35 \mathrm{~mm}$

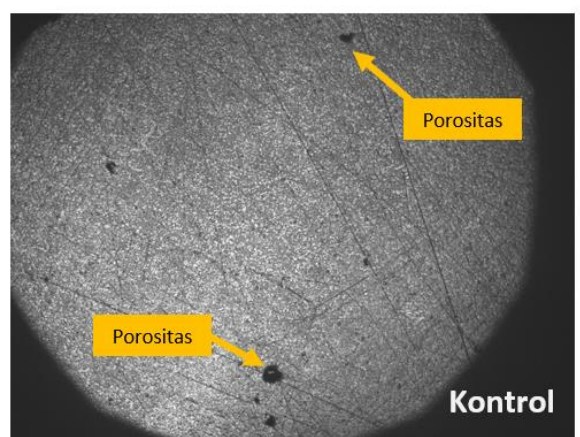

Gambar 7. Foto mikro porositas spesimen control

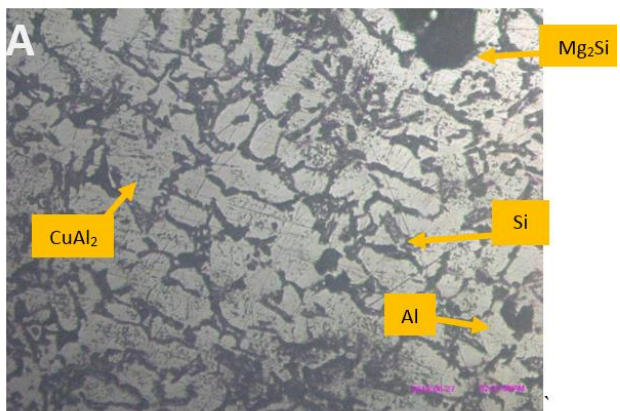

Gambar 8. Struktur mikro spesimen variasi tanpa saluran penambah

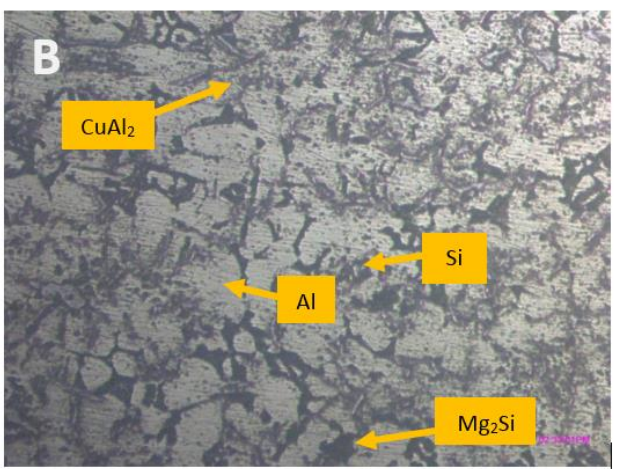

Gambar 9. Struktur mikro spesimen variasi saluran penambah diameter $15 \mathrm{~mm}$

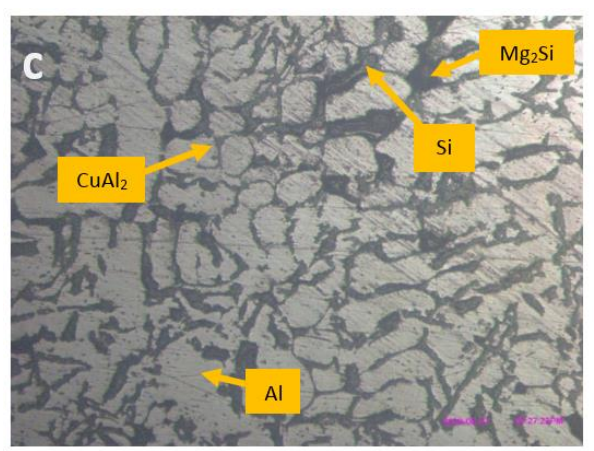

Gambar 10. Struktur mikro spesimen variasi saluran penambah diameter $25 \mathrm{~mm}$

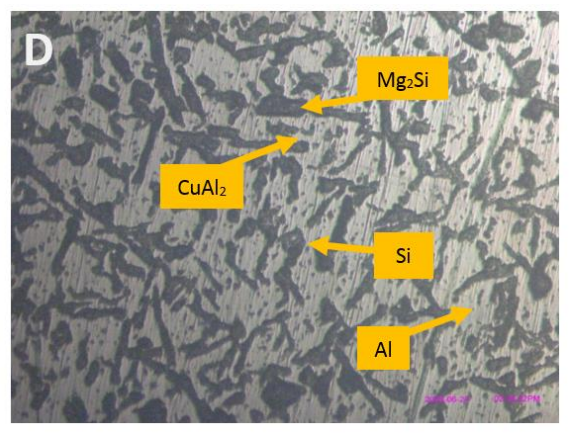


Gambar 11. Struktur mikro spesimen saluran penambah variasi diameter $35 \mathrm{~mm}$

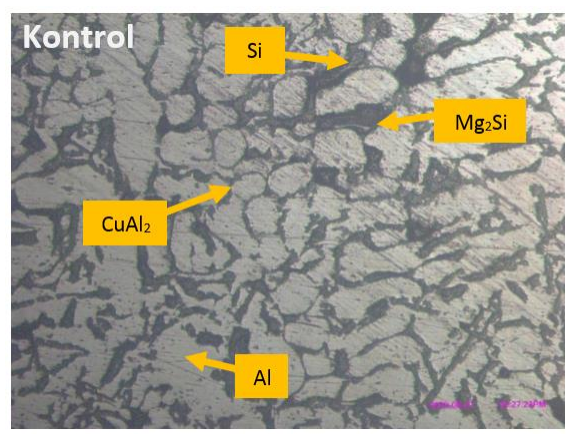

Gambar 12. Struktur mikro specimen control

\section{Pembahasan}

Pengujian cacat porositas menunjukkan adanya perubahan nilai porositas setelah diberikan perlakuan. Dapat dilihat adanya pengaruh penambahan saluran penambah terhadap nilai porositas, nilai porositas terbaik dengan penambahan saluran penambah dengan diameter $35 \mathrm{~mm}$ sebesar 37,97 $\%$ dan nilai porositas terburuk adalah variasi tanpa saluran penambah sebesar $33,07 \%$. Hal ini sesuai dengan sebagai penelitian Fasya, F., \& Iskandar, N. (2015), yang menyatakan nilai porositas yang bervariasi dan cukup tinggi tersebut dapat dikatakan dikarenakan pori-pori yang terbentuk membesar, faktor waktu penuangan yang berbeda-beda sehingga adanya udara yang terperangkap, dan perbedaan kandungan kotoran (slag) yang berbeda-beda juga pada pasir cetakakan karena cetakan yang digunakan juga berbeda-beda untuk tiap pengecoran. Pada proses pengecoran logam memungkinkan munculnya gasgas yang bereaksi menjadi komposisi kimia atau menjadi rongga-rongga udara. Gas tersebut muncul karena adanya udara yang terjebak selama proses penuangan, kontak antara logam cair dengan cetakan, atau dari lapisan yang terbentuk selama proses pembekuan sebagai hasil dari reaksi kimia atau perubahan mampu larut logam cair terhadap suhu (Beeley, 2001: 48). Dengan semakin besarnya saluran penambah dapat mengurangi kotoran (slag) karena kotoran akan terangkat keatas atau menuju saluran penambah dan mengurangi pori-pori akibat permaebilitas pasir cetakan.

Berdasarkan foto mikro yang telah dilakukan menunjukkan bahwa foto struktur mikro pada spesimen dengan tanpa saluran penambah memiliki susunan Al dan Si-Cu-Mg yang lebih renggang dan bentuk Si-Cu-Mg yang pendek dan lebar. Hal ini dikarenakan laju pembekuan pada logam cair pada cetakan dengan tanpa saluran penambah berjalan lambat. Adapun karakteristik hasil coran setelah diketahui fasa-fasanya adalah Fasa Al (berwarna terang) adalah larutan padat primer. Sedangkan fasa Si-Cu-Mg (Berwarna kelabu gelap), dengan adanya fasa ini mempermudah proses pengecoran, meningkatkan ketahanan korosi, dan meningkatkan sifat mampu cor.

Struktur mikro yang terbentuk pada spesimen dengan saluran penambah diameter $15 \mathrm{~mm}$ memiliki susunan $\mathrm{Al}$ dan Si-Cu-Mg yang rapat dengan ukuran Si-Cu-Mg yang kecil dan agak panjang. Hal ini dikarenakan laju pada logam cair saat pengecoran berlangsung sedikit lambat. Adapun karakteristik hasil coran setelah diketahui fasa-fasanya adalah Fasa Al (berwana terang) adalah larutan padat primer. Sedangkan fasa Si-Cu-Mg (Berwarna kelabu gelap), dengan adanya fasa ini mempermudah proses pengecoran, meningkatkan ketahanan korosi, dan meningkatkan sifat mampu cor.

Pada spesimen dengan saluran penambah diameter $25 \mathrm{~mm}$ dan $35 \mathrm{~mm}$ menunjukkan struktur mikro dengan susunan Al dan Si yang rapat dengan ukuran Si yang lebih kecil tetapi memiliki bentuk yang panjang. Hal ini 
dikarenakan kadar air pada cetakan yang banyak dan menyebabkan laju pembekuan logam cair menjadi sedikit cepat. Adapun karakteristik hasil coran setelah diketahui fasa-fasanya adalah Fasa Al (berwana terang) adalah larutan padat primer. Sedangkan fasa Si-Cu-Mg (Berwarna kelabu gelap), dengan adanya fasa ini mempermudah proses pengecoran, meningkatkan ketahanan korosi, dan meningkatkan sifat mampu cor.

Paduan Aluminium-Silikon yang mempunyai kandungan silikon kurang dari 12\% merupakan AI-Si Hipoeutektik sedangkan paduan yang memiliki kandungan lebih dari $12 \%$ merupakan Al-Si Hipereutektik

Menurut Zeren, M. dalam Nindhia (2010: 31), Paduan aluminium yang digunakan untuk ketahanan aus adalah paduan aluminium-silikon. Paduan hipoeutektik mengandung fase aluminium primer yang lunak dan ulet serta mengandung fase silikon yang keras dan getas sesuai dengan reaksi eutetektik. Fase silikon inilah yang memberikan kontribusi terhadap ketahanan aus yang baik bagi paduan ini. Silikon bersifat tidak larut dalam aluminium. Paduan Al-Si Hipereutektik merupakan paduan yang paling banyak dipakai untuk keperluan ketahanan terhadap aus mengandung partikel silikon primer berukuran besar dan bersudut di samping juga mengandung eutektik silikon. Partikel silikon primer ini menghasilkan ketahanan aus yang baik bagi paduan ini.

\section{SIMPULAN}

1. Ada pengaruh penambahan variasi volume saluran penambah (riser) terhadap porositas hasil pengecoran. Porositas yang terbaik ditunjukkan oleh spesimen hasil coran dengan variasi saluran penambah diameter $35 \mathrm{~mm}$ sebesar $37,97 \%$ dikarekan dengan semakin besarnya saluran penambah dapat mengurangi kotoran (slag) karena kotoran akan terangkat keatas atau menuju saluran penambah dan mengurangi poripori akibat permaebilitas pasir cetakan.

2. Ada pengaruh penambahan variasi volume saluran penambah (riser) terhadap struktur mikro hasil pengecoran. Struktur mikro yang terbaik ditunjukkan oleh spesimen hasil coran dengan variasi saluran penambah diameter $35 \mathrm{~mm}$ dibandingkan dengan variasi saluran penambah diameter $25 \mathrm{~mm}$ dan saluran penambah diameter $15 \mathrm{~mm}$ serta variasi tidak menggunakan saluran penambah dibuktikan dengan pembentukan fasa struktur yang lebih rapat dan merata. Namun struktur mikro dari tutup motor listrik lebih baik dari pada spesimen hasil pengecoran ditunjukkan dari susunan fasa yang terbentuk lebih homogen.

\section{SARAN}

1. Lebih disarankan untuk melakukan pengecoran dengan tungku induksi agar pelelehan dari benda uji lebih cepat, efisien dan lebih maksimal.

2. Dalam pengujian keausan dianjurkan memilih garis terbesar sehingga yang didapat adalah nilai keausan terbesarnya.

3. Perlu diadakan penelitian tentang struktur butir, cacat lubang jarum dan pengaruh jenis baterai yang digunakan sehingga data penelitian lebih lengkap dan akurat. 
Beeley, P. 2001. Foundry Technology Second Edition. London: Butterworth Heinemann.

Fasya, F., \& Iskandar, N. (2015). Melt Loss dan Porositas pada Aluminium Hasil Daur Ulang. Jurnal Teknik Mesin, 3(1), 44-50.

Gaspari, J. 1999. Making The Most Od Aluminium Scrap. New York. Mechanical Engineering.

Jin, C. K., Seo, H. Y., \& Kang, C. G. 2017. Heating system for riser size minimizing in sand casting process and its experimental verification. Metals, 7(4), 130.

Nindhia, T. G. T. (2010). Studi Struktur Mikro Silikon dalam Paduan Aluminium-Silikon pada Piston dari Berbagai Merek Sepeda Motor. Jurnal Energi Dan Manufaktur.

Rizuan, M., Shafiee, M., Yussni, M., Hashim, B., Nusyakirin, M., \& Said, B. (2009). Effects of gating design on the mechanical strength of thin section castings, 1-4.

Tjitro, S. 2001. Pengaruh Bentuk Riser Terhadap Cacat Penyusutan Produk Cor Aluminium Cetakan Pasir. Jurnal Teknik Mesin, 3(2), 41-46. 